\title{
General Practitioners must know about Quaternary Prevention
}

Harshal Tukaram Pandve*

Department of Community Medicine, Smt. Kashibai Navale Medical College, Narhe, Pune, India

${ }^{*}$ Corresponding author: Dr. Harshal Tukaram Pandve, MBBS, MD, Associate Professor, Dept. of Community Medicine, Smt. Kashibai Navale Medical College, Narhe, Pune, Tel: 912024106268; E-mail: dr_harshalpandve@yahoo.co.in

Rec date: May 20, 2016, Acc date: May 26, 2016, Pub date: June 02, 2016

Copyright: (C) 2016 Pandve HT. This is an open-access article distributed under the terms of the Creative Commons Attribution License, which permits unrestricted use, distribution, and reproduction in any medium, provided the original author and source are credited.

\section{Commentary}

With scientific advances in medical sciences over the years many new diagnostic as well as treatment modalities are developed with many patients getting quality of life which was not available before. On the other hand it is also observed that with advances in medical sciences the patient care is becoming more and more specialized and many new super specialty services coming up. As result of such fragmented medical services, it is not uncommon for patients to see several specialists who do not communicate with each other. One consequence of this is that the patient becomes a victim of the "findings of examinations" and the side effects [1]. There are few question related to it, first is, how may patient actually need super specialty services and second is whether general practitioners also known as family physician or family doctors, can take care many patient which are needlessly referred to more specialized services.

As rightly pointed out that general practitioners provide person centered, continuing, comprehensive and coordinated whole person health care to individuals and families in their communities [2], their role is also crucial in disease prevention. Primordial, Primary, Secondary and Tertiary Prevention are the well-known levels of disease prevention and an addition of Quaternary prevention is noteworthy. Quaternary prevention a "higher" level of prevention suggested first by Jamoulle and Ronald. Quaternary prevention is defined as "action taken to identify patient at risk of over-medicalization, to protect him from new medical invasion, and to suggest him interventions ethically acceptable." The concept of quaternary prevention makes it easier to "identify patient at risk of over-medicalization." [3]. It is based on the principle of "primum non nocere" meaning "first, do no harm. "Unnecessary tests, treatments and procedures do not add value to care. In fact, they take away from care by potentially exposing patients to harm, leading to more testing to investigate false positives and contributing to stress and avoidable costs for patients. These unnecessary tests, treatments and procedures put increased strain on the resources of a health care system [4]. A study conducted by the Fuentes et al to determine the attitudes, perceptions and awareness towards Quaternary Prevention among family doctors in Lima Peru concluded that there were positive perceptions towards Quaternary Prevention [5]. Such studies are rare in other parts of the world the main reason being lack of awareness about Quaternary Prevention in the general practitioners.

To conclude with as rightly said, caring and understanding patient's world is still the first duty of the family doctors. Unfortunately the next duty is now to protect patients against medicine [6]. It is pertinent to generate awareness regarding Quaternary Prevention in the medical fraternity especially among the general practitioners popularly known as family doctors as they are the first point of contact for majority of the patients. It is important for the associations of general practitioners to take this task of percolating the concept of Quaternary Prevention among their members and creating an attitude and promoting the practice of principles of Quaternary Prevention among their members.

\section{References}

1. Gervas J (2013) Safe and sanitary and free from unnecessary interventions. Barcelona : Lynx Books.

2. What is General Practice?

3. Jamoulle M, Roland M (1995) Quaternary prevention. Paper presented at the Hong-Kong Meeting of the Wonca Classification Commitee.

4. Kuehlin T, Sghedoni D, Visentin G, Gérvas J, Jamoulle M (2010) Quaternary prevention: a task for general practitioner. Primary Care 10: 350-354.

5. Fuentes MSC, Zamalloa COZ, Relchert S, Gill D (2016) Attitudes, perceptions and awareness concerning quaternary prevention among family doctors working in the Social Security System, Peru: a crosssectional descriptive study. Medwave 16: e6433.

6. Jamoulle M (2015) Quaternary prevention, an answer of family doctors to overmedicalization. Int J Health Policy Manag 4: 61-64. 